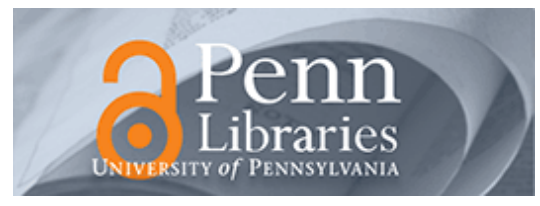

University of Pennsylvania

ScholarlyCommons

PSC Working Paper Series

9-5-2014

\title{
Growing Educational Differentials in the Retreat from Marriage among Korean Men
}

Hyunjoon Park

University of Pennsylvania, hypark@sas.upenn.edu

Jae Kyung Lee

Ewha Women's University

Follow this and additional works at: https://repository.upenn.edu/psc_working_papers

Part of the Demography, Population, and Ecology Commons, Feminist, Gender, and Sexuality Studies Commons, and the Korean Studies Commons

Park, Hyunjoon and Lee, Jae Kyung, "Growing Educational Differentials in the Retreat from Marriage among Korean Men" (2014). PSC Working Paper Series. 57.

https://repository.upenn.edu/psc_working_papers/57

Park, Hyunjoon and Jae Kyung Lee. 2014. "Growing Educational Differentials in the Retreat from Marriage among Korean Men." PSC Working Paper Series, WPS 14-5. http://repository.upenn.edu/psc_working_papers/57.

This paper is posted at ScholarlyCommons. https://repository.upenn.edu/psc_working_papers/57

For more information, please contact repository@pobox.upenn.edu. 


\title{
Growing Educational Differentials in the Retreat from Marriage among Korean Men
}

\begin{abstract}
Applying discrete-time hazard models to person-year data constructed from $1 \%$ microdata sample of 2010 Korean Census, we explore how men's education affects their transition to first marriage, and how the relationship between education and marriage has changed across three 10-year birth cohorts of Korean men born from 1946 to 1975 . Currently, there is only limited knowledge on how education is related to marriage formation and how the effect is contingent upon macro contexts of education, economy, and family among East Asian men. We find that the high educated delay marriage until later ages but catch up to the extent to which they are eventually more likely to marry than the low educated. There is a continued trend across cohorts toward the delay and avoidance of marriage at all educational levels. However, the trend of retreat from marriage has been more substantial for men with high school or less education compared to men with a university degree, leading to growing educational gaps over time in marriage. We discuss the findings in the contexts of deteriorating economic prospects of Korean men with lower education and also the declining pool of potential spouses for the low educated.
\end{abstract}

\section{Keywords}

Marriage, Korea, Educational Differentials, Gender, 2010 Korean Census

\section{Disciplines}

Demography, Population, and Ecology | Feminist, Gender, and Sexuality Studies | Korean Studies | Social and Behavioral Sciences | Sociology

\section{Comments}

Park, Hyunjoon and Jae Kyung Lee. 2014. "Growing Educational Differentials in the Retreat from Marriage among Korean Men." PSC Working Paper Series, WPS 14-5. http://repository.upenn.edu/ psc_working_papers/57. 


\title{
Growing Educational Differentials in the Retreat from Marriage among Korean Men
}

\author{
Hyunjoon Park \\ Associate Professor \\ Department of Sociology \\ University of Pennsylvania \\ Jae Kyung Lee \\ Professor \\ Department of Women's Studies \\ Ewha Womans University
}

* Please direct all correspondence to Hyunjoon Park (hypark@sas.upenn.edu), Department of Sociology, University of Pennsylvania, 3718 Locust Walk, Philadelphia, PA 19104. This

research was supported by the Academy of Korean Studies (Korean Studies Promotion Service) Grant funded by the Korean Government (Ministry of Education) (AKS-2010-DZZ-2101). We thank James Raymo and Aimeé Dechter for their useful comments as well as Jaesung Choi for his help for data management. 


\title{
Growing Educational Differentials in the Retreat from Marriage among Korean Men
}

\begin{abstract}
Applying discrete-time hazard models to person-year data constructed from $1 \%$ microdata sample of 2010 Korean Census, we explore how men's education affects their transition to first marriage, and how the relationship between education and marriage has changed across three 10year birth cohorts of Korean men born from 1946 to 1975. Currently, there is only limited knowledge on how education is related to marriage formation and how the effect is contingent upon macro contexts of education, economy, and family among East Asian men. We find that the high educated delay marriage until later ages but catch up to the extent to which they are eventually more likely to marry than the low educated. There is a continued trend across cohorts toward the delay and avoidance of marriage at all educational levels. However, the trend of retreat from marriage has been more substantial for men with high school or less education compared to men with a university degree, leading to growing educational gaps over time in marriage. We discuss the findings in the contexts of deteriorating economic prospects of Korean men with lower education and also the declining pool of potential spouses for the low educated.
\end{abstract}




\section{INTRODUCTION}

During the past decades men and women in South Korea (Korea, hereafter) have increasingly postponed marriage: the mean age at first marriage has increased four years over two decades from 1990 to 2010 for both men (27.8 to 31.8) and women (24.8 to 28.9) (Statistics Korea 2011). The trend of delayed marriage in Korea is evident given that it has taken more than three decades for the median age of first marriage among men in the United States to increase by four years from 24.2 in 1977 to 28.2 in 2010 (US Census Bureau 2011). Recent evidence even seems to suggest that the claim of universal marriage may not hold up among Korean men in coming years. According to our own calculations on the basis of census tabulations provided by Statistics Korea, the proportion of men aged 45-49 who never married was only 0.8 percent in 1990 indicating the level of universal marriage. Two decades later, however, the corresponding percentage increased to 7.5 percent. Considering that almost everyone had married until very recently, this trend toward later and less marriage can mean fundamental transformation of family behaviors in Korea.

Despite growing attention to later and less marriage, however, little known is whether the trend toward later and less marriage appears similarly across different socioeconomic groups or whether the trend is particularly evident for a specific socioeconomic group than others in the Korean context, especially among men. In fact, there is a dearth of literature on socioeconomic differentials in marriage among men, not only for Korea but also for other neighboring Asian countries. Several studies have examined how women's socioeconomic characteristics, particularly educational attainment, affect their transition to marriage in East Asia (Chang and Li 2011; Fukuda 2013; Park, Lee, and Jo 2013; Raymo 2003). However, much limited is research on how men's socioeconomic characteristics are related to their marriage chances in East Asia. 
This lack of scholarship on marriage among men seems to reflect the general tendency of focusing on women but ignoring men when studying family behaviors such as marriage and fertility (Lloyd and South 1986; Oppenheimer, Kalmijn, and Lim 1997). Although several studies after Oppenheimer et al. (1997) have examined the effects of men's socioeconomic characteristics on their marriage either in the United States and Europe (Kalmijn 2011; Oppenheimer 2003; Sweeney 2002; Xie et al. 2003), this balanced interest to men's marriage behaviors has not been shown for men in East Asia (except Woo 2009).

Particularly troublesome is the paucity of research that examines how the relationship between men's education (and other socioeconomic characteristics) and marriage has changed over time. Obviously, economic and cultural contexts of marriage have shifted considerably over time in many countries, suggesting that not only marriage has been increasingly delayed or forgone but also the effects of men's socioeconomic characteristics on marriage might have changed as well. Comparing effects of economic prospects on marriage between US men born in 1950-54 and those born in 1961-65, for instance, Sweeney (2002) found that although the importance of earning for marriage hardly changed between the two cohorts, the relationship between education and marriage became stronger for the later cohort. Although they did not examine transition to marriage at the individual level, a recent study of Manning, Brown, and Payne (2013) looked at changing median ages by educational groups among US men (as well as women) from the mid 1980 to the late 2000s. However, except for these studies, most studies of men's marriage looked at marriage behaviors of a specific cohort (e.g., Oppenheimer et al. 1997; Oppenheimer 2003; Xie et al. 2003), leaving unexplored how the effects of men's socioeconomic characteristics on marriage have changed across cohorts who entered the ages of marriage under different contexts of family and economy within a country. ${ }^{1}$ Contrastingly, 
studies of marriage among women have paid serous attention to changing relationships between women's socioeconomic characteristics (especially education) and marriage, advancing our understanding of how the relationship may be contingent on society's economic or gender-role contexts (Goldstein and Kenney 2001; Park et al., 2013; Sweeney 2002; Torr 2011).

In this study, we investigate how men's educational attainment affects their transition to first marriage in Korea, and how the effect of education on marriage has changed over time. Although we acknowledge that educational attainment is only one of various socioeconomic characteristics of men that can influence their marriage chances, it has been of a major focus of many studies that addressed socioeconomic differentials in transition to marriage (Raymo 2003; Schoen and Cheng 2006). Specifically, using large data from Korean Census 2010, we compare the relationship between educational attainment and marriage across three 10-year birth cohorts of Korean men born in 1946-55, 1956-65, and 1966-75. Given scant research on long-term trends in the effects of men's socioeconomic characteristics on marriage, our comparison of the education-marriage relationship over three decades adds value to the literature. ${ }^{2}$

Korean men of three different cohorts reached marriage ages under substantially different contexts of education, family, and economy, which provide a useful case with which to address how the way in which men's education affects marriage is shaped by macro contexts. As will be described below in greater detail, the expansion of tertiary education and shifting economic structure toward information and knowledge-based economy have deteriorated economic prospects of Korean men without tertiary education. The economic crisis and rising economic inequality since the end of 1990s, moreover, have adversely affected employment instability of young men, particularly with low education. Note that in the context of rising economic inequality in the United States, emergent is the social divide in marriage (Linn 2013; Manning et 
al., 2013): "Y[oung] adults with greater earning potential, who can afford the capstone celebration, are still marrying in large numbers, while those with poorer economic prospects are holding off" (Cherlin 2013: SR7). Therefore, the Korean society, which has experienced similar economic changes toward diverging economic prospects between those with high and low education, offers an opportunity to examine emergence of social divide in marriage behaviors.

Another interesting context of Korean society, which may be relevant for changing marriage rates especially among men with the lowest level of education, is a prevalent tendency for women to marry men with higher education and/or socioeconomic status (female hypergamy) (Choe 1998; Park and Smits 2005). When this tendency for female hypergamy remains more or less constant over time, the rising level of Korean women's education can mean the declining pool of potential spouses for men with the lowest level of education. Raymo and Iwasawa (2005) tested this marriage market mismatch hypothesis for highly educated women in Japan, who faced this problem of reduced pool of potential spouses. Since Raymo and Iwasawa (2005) did not examine men's marriage, our current study may provide additional evidence for the potential of the marriage market mismatch hypothesis to explain changing marriage rates by education. Of course, it is not our goal in this paper to directly evaluate the marriage market mismatch hypothesis. We simply consider the hypothesis as a potential explanation of what might have happened to marriage particularly of those with the lowest level of education in Korea.

\section{CHANGING CONTEXTS OF EDUCATION AND ECONOMY IN KOREA}

Studies in the United States have consistently shown that men's socioeconomic characteristics are positively associated with marriage formation (Oppenheimer et al. 1997; Schoen and Cheng 2006; Xie et al. 2003), although the effects of women's socioeconomic 
characteristics are somewhat inconsistent. Regardless of methods to estimate the effect, "[a]ll empirical methods suggests that men's economic opportunities exert a strong influence on marriage and divorce. Improved male earnings appear to hasten marriage and may also increase the overall prevalence of marriage" (Ellwood and Jencks 2004: 47; see also Burstein 2007). Most studies have found that as an indicator of economic prospects, men's education is positively associated with the likelihood of marriage. The positive relationship between men's education and marriage is consistent with the prediction by the economic model of marriage that emphasizes benefits of marriage due to specialization of spouses (Becker 1981; Ellwood and Jencks 2004; Burstein 2007). Because of men's specialization in labor market, men with higher economic prospects (including higher education) are likely to have a higher probability of marriage than men with poorer prospects.

This economic model of marriage may explain the marriage pattern particularly well in Korea (and possibly other East Asian countries) where traditional gender division of labor between work and family has been comparably strong, albeit weakening over time (Brinton 2001). Although Korean women's labor force participation has steadily increased over time, Korean women still show a relatively low level of labor force participation: the female labor force participation rate was fourth lowest in Korea among 34 OECD countries following Chile, Italy, and Turkey (OECD 2012). Importantly, Korea still displays the M-shaped pattern of female labor force participation by age, which suggests that a large share of women leave the labor market upon marriage and childbearing (and then return to the labor market only after their kids get older) (Brinton 2001; Yang and Ban 2012). The overall low level of women's labor force participation and interruption of women's occupational careers due to marriage and childbearing are particularly surprising given that Korean young women are nowadays one of the 
most educated populations in the word (Park 2007a). Park and Raymo (2013: 113) conclude that "gender asymmetry in work and family roles remains pronounced in Korea." In this context of strong gender division of labor, men's position in labor market may be a particularly important factor for marriage. Therefore, similar to the US (or perhaps even more so), men's education is expected to be positively associated with marriage in Korea.

However, as Ellwood and Jencks (2004) pointed out, the economic model is mostly to explain the overall likelihood of marriage but may not be so adequate to explain the pattern of delaying marriage. The relationship between men's educational attainment and marriage may change across age. Even if highly educated men are eventually more likely to marry than their counterparts of lower education, they may marry much later to complete higher education and to establish a stable job career before marriage. In other words, men with higher education are less likely to marry than men with lower education at younger ages (i.e. the relationship between education and marriage is negative) but catch up at some ages from which the relationship between education and marriage is reserved. When later marriage (delay) and less marriage (avoidance) are distinguished, the way in which educational attainment is related to marriage can be better understood (Ellwood and Jencks 2004). In the current study, we use an appropriate analytic strategy that allows us to examine educational differentials in the likelihood of marriage across different age ranges.

Several studies in the United States have explored not only the relationship between men's education and marriage but also its change over time. Has the positive impact of education on marriage become even more evident in recent years? As described earlier, Sweeney's (2002) study found a stronger effect of education on men's marriage for those born between 1961 and 1965 than their counterparts born between 1950 and 1954 in the United States. 
This enlarging difference in marriage between US men with higher and lower education may reflect the growing impact of education on labor market positions and life standards (Fisher and Hout 2006). Although men at both high and low ends of educational distribution have delayed marriage, a particularly evident trend is the retreat from marriage among men (and also among women) with lower education whose economic prospects have increasingly deteriorated (Manning, Brown, and Payne 2013).

Economic prospects between Korean men with the highest level of education and the lowest level have diverged, similar to the pattern in the United States, over time. Most of all, the expansion of higher education has been considerable since the 1980s (particularly during 1990s) (Park 2007b). Our own calculation with the 2010 Korean Census data indicates that 20 percent of men born between 1946 and 1955 had higher education in either junior colleges or universities, while the corresponding percentage increased to 53 percent among the most recent cohort born between 1966 and 1975. Meanwhile, along with rapid economic growth, the occupational structure in Korea has also considerably shifted toward information and knowledge-based economy where higher education has increasingly become valuable. In 1963 more than three out of five employed people in Korea were working in the agricultural, forestry, and fishery industry, while four decades later, only one out of ten workers were employed in the same industry (KOSIS 2013). On the other hand, the percentage of workers with a professional, technical, or managerial job increased from 4 percent in 1960, through 5 percent in 1980 to 19 percent in 2000 (Hong 2003).

Along with the economic shift, the rapid expansion of Korean education has likely dimmed labor market positions of the low educated, especially those without tertiary education. Specifically, the labor force participation rate of Korean men who did not graduate from high 
school (i.e., had primary or middle school education only) precipitated from 73 percent in 1980 through 57 percent in 2000 to 48 percent in 2010 (KOSIS 2013). Although less substantial than their peers with no high school education, Korean men with a high school diploma only also suffered from the reduced economic opportunity: the labor force participation rate dropped from 81 percent in 1980 through 78 percent in 2000 to 75 percent in 2010. The rapid reduction in the economic opportunity among Korean men with low education is outstanding in international comparison (Yoon 2012). Although men who had college education either in junior colleges or universities also experienced a reduction in the labor force participation rate during the same period, in both 2000 and 2010, still 89 percent of them were in labor force. Moreover, evidence shows that economic returns to a university degree have increased from the mid-1990s, leading to growing income differentials by educational attainment (Cheon 2013).

Moreover, growing economic difficulties and job insecurity during the period of economic crisis might have further decreased economic prospects of men with low education. The Korean economy, which had grown fast earning a reputation as one of Asian Tigers, was abruptly hit by economic crisis in late 1997. The economic crisis has had far-reaching impacts on various aspects of individuals' social life beyond deteriorating economy. In particular, studies have shown a consistent trend of increased income inequality since outbreak of the economic crisis (Hyun and Lim 2005; Jomo 2006). In response to the economic crisis, the whole economic structure has been transformed, and particularly employment structure has been significantly shifted toward increased deregulation and flexibility in labor market. In the result, the share of non-regular (including temporary and daily) employment in labor market has increased: according to an estimate by the Korean Labor Institute, the share of non-regular 
workers in labor force increased from 27 percent in 2002 to 37 percent in 2004 (the absolute number of non-regular workers increased by 1.5 million between the two years) (Shin 2013).

In short, in the contexts of the rapid expansion of higher education, the shift of economic structure toward information and knowledge-based economy, and increasing economic insecurity and inequality during the economic crisis, economic prospects of Korean men without a college degree have increasingly deteriorated relative to their counterparts with a college degree.

Considering previous studies that highlight the positive impact of men's economic prospects on marriage (Burstein 2007; Ellwood and Jencks 2004) and also studies that particularly show the influence of labor market conditions on marriage (Harknett and Kuperberg 2011; Lichter, McLaughlin, and Ribar 2002), therefore, we reason that the likelihood of marriage has likely diverged over time between men with higher and lower educational attainment. We, furthermore, expect that educational differentials in marriage chances should be particularly evident for the most recent cohort of our study who became the ages of marriage under aggravated labor market difficulties during the economic crisis.

However, the explanation of changing effects of men's education on marriage, which focuses on changing economic values of men's education in labor market, can be complemented by simultaneously looking at what has happened among women. As described above, education expansion in Korea during the last decades among women has been as substantial as among men, considerably narrowing the gender gap in the share of college-educated population (Park 2007b; also see Kye and Mare 2012). This trend of increasing women's education has likely changed the pool of women for marriage of men with the lowest level of education. As previous studies have suggested, in Korea (and other East Asian countries like Japan) there is a strong tendency for husbands to have a higher level of education than wives, possibly reflecting patriarchal 
culture (Choe 1998; Park and Smits 2005; Raymo and Iwasawa 2005). In the context where women tend to marry up with respect to education and other socioeconomic indicators, men with the lowest level of education might have faced increasing difficulty in marrying as the pool of women, who have a lower level of education than men, has increasingly decreased. ${ }^{3}$ Importantly, gender asymmetry in marriage has not changed over time. According to Park and Smits' (2005) study, the tendency for women to marry up has persisted across six decades from 1930s to 1990s marriage cohorts. Studying Japanese women's marriage, Raymo and Iwasawa (2005) showed that the reduced availability of highly educated men as potential spouses for highly educated women, along with expansion of university education among Japanese women, accounted for some of the declining marriage rate of Japanese women with a university degree. We expect that the similar reasoning can be applied to men with the lowest level of education.

\section{DATA AND METHODS}

\section{Data and Variables}

We compare the relationship between education and marriage across three 10-year birth cohorts of Korean men born in 1946-55, 1956-65, and 1966-75 using $1 \%$ microsample data from 2010 Korean Cesus. The years, when those of middle point in each cohort became the age 30, were 1980, 1990, and 2000, respectively, well representing historical differences in educational and economic contexts as described above. The 2010 Census asked respondents of the age of first marriage if they ever married. From the original sample of men born between 1946 and 1975, we excluded 414 men who married before the age 18. We, then, dropped additional 84 men who did not report their age of marriage even though they ever married. In the end, we 
have a total of 102,832 men for the final sample $(25,538$ for the $1946-55$ cohort; 38,386 for the 1956-65 cohort; and 38,908 for the 1966-75 cohort).

We classify men's educational attainment into four categories: less than high school, high school completion, junior college completion, and university completion. This four-category classification of educational attainment reflects major educational stages in Korean educational system. In particular, use of census data facilitates us to separately look at men with the lowest level of education (i.e., less than high school education) whose number is increasingly small for recent cohorts due to educational expansion. In a substantive perspective, we consider it important to examine how men who do not have a high school diploma and thus are increasingly marginalized in expanding Korean education fair in marriage market.

To construct the variable of the 'completed' level of educational attainment, we used information on both the highest level of education ever attended and status of completion (i.e., whether they graduated the highest level) as reported in the Census. It could be problematic to assume that the highest level of education reported in the Census is actually the level of education one had at time of marriage. Some people might have returned to school after marriage and obtained a college degree, for instance. However, previous studies indicated that it is rare in Korean school system for adults to return to school once left (Park 2013). In other words, given the limited degree of educational upgrading in Korean education, we consider that our assumption should not be too unreasonable. However, since the Korean Census did not collect information on one's educational history, we are not able to directly validate our assumption. Note that once we dropped those who had missing information on the age of first marriage or who married before the age 18 , we did not have any further missing cases on educational attainment (everyone reported the highest level of education attended, and we treated 
832 men, who reported the highest level of education but did not report status of completion, as if they did not graduate the given level of education). In short, in both measures of educational attainment and the age of marriage, which are critical variables in our analysis, our data do not have many missing cases.

We apply the discrete-time hazard models for transition to first marriage with the personyear data rearranged from the original individual-level data. The total number of person-years is $1,224,335$. We model the duration until first marriage among those who were not married until the age 17. Men are followed up from the age 18 until the age of marriage if they were ever married. Otherwise, they are censored at the age in 2010 or at the age of 39 whichever comes first. The most recent cohort members born between 1966 and 1975 were in the ages of 35 to 44 in 2010. Although we could have the age 35 as the timing of censoring, which would yield no censored case at all, we rather decided to use additional information of half of the cohort by extending the timing of censoring to the age 39 . We conducted a sensitivity analysis by using observations only up to the age 35 for all cohorts, and the result was very similar to what we present in the current paper. To specify the effect of duration until the age of marriage (or censoring), we use a linear spline with knots at 7 and 12 years since the age 18 (i.e., at ages 25 and 30). Our preliminary analysis showed that the ages, at which knots should be located, were similar across the three cohorts. ${ }^{4}$ The risk of transition to marriage is specified to change linearly within each spline segment.

Finally, we include school enrollment status as a time-varying covariate to better estimate the effect of educational attainment on marriage. As Raymo (2003) emphasized in his study of Japanese women's marriage, the effect of school enrollment on marriage should be separated from the effect of educational attainment that reflects differences in socioeconomic resources and 
career prospects between individuals of higher and lower education. Although exact dates of starting and ending each level of educational attainment are not available from the 2010 Census data, we construct a time-varying dummy variable of school enrollment for each age from the age 18, using the year of birth and the highest level of education attained. Following the similar strategy of Raymo (2003) for Japanese women and of Park et al. (2013) for Korean women, we assume that a man continued his schooling from age 6 to high school graduation and then to college for those who made transition to tertiary education without any interruption. However, considering mandatory compulsory military service that basically all Korean men have to do typically for two years, we add two more years to the period of higher education enrollment. ${ }^{5}$ Table 1 presents descriptive statistics of major variables by cohorts from the person-years data.

\section{TABLE 1 ABOUT HERE}

\section{Methods}

We estimate five discrete-time hazard models (logit models) in sequence for transition to first marriage similar to the strategy previously used by Raymo (2003) for marriage in Japan and by Woo (2009) and Park et al. (2013) for marriage in Korea. By comparing the five models, we test full interactions among duration, education, and cohort to assess the extent to which the relationship between education and marriage varied by duration and cohort, which is the main focus of the current study.

Model 1: $\log \left(\frac{p_{i t}}{1-p_{i t}}\right)=$ Dur $_{i}(t)+$ Edu $_{i}+$ Cohort $_{i}+$ Enrollment $_{i}(t)$ 
Model 2: $\log \left(\frac{p_{i t}}{1-p_{i t}}\right)=$ Model $1+$ Cohort $_{i} \times E d u_{i}$

Model 3: $\log \left(\frac{p_{i t}}{1-p_{i t}}\right)=\operatorname{Model} 2+\operatorname{Dur}_{i}(t) \times E d u_{i}$

Model 4: $\log \left(\frac{p_{i t}}{1-p_{i t}}\right)=$ Model 3+Dur $(t) \times$ Cohort $_{i}$

Model 5: $\log \left(\frac{p_{i t}}{1-p_{i t}}\right)=$ Model 4 + Dur $_{i}(t) \times E d u_{i} \times$ Cohort $_{i}$

where the $\log$ odd of marrying of man $i$ at a time (age) $t$ (i.e., $\mathrm{t}^{\text {th }}$ year since the age 18) given being unmarried at time t-1 are predicted by education, cohort, duration (and interactions among them) and enrollment status. In the equations above, both duration and school enrollment are time-varying covariates, while education and cohort are time invariant.

Model 1 includes the main effects of duration, education, cohort and school enrollment, while Model 2 adds interaction terms between cohort and education. With the result of Model 2, we can assess the extent to which the effect of education on marriage has changed (or remained) across three cohorts. In Model 3, we additionally allow the effect of education on marriage to vary across duration since the age 18 (i.e., age). As discussed above, a critical question in understanding the relationship between education and marriage is whether the relationship is reversed in later ages as men with higher education catch up. With Model 3 we can addresses this question. In addition to the interactions between cohort and education (Model 2) and the interactions between duration and education (Model 3), Model 4 assesses whether cohort differences in transition to marriage vary across duration by including interaction terms between duration and cohort. Finally, Model 5 posits full interactions among duration, cohort, and 
education to obtain the detailed and completed picture of change in the effect of education on marriage by duration and cohort.

For model comparisons, we rely on BIC' (Bayesian Information Criterion) that is based on the log-likelihood ratio (LR) chi-squared statistic (Long and Freese 2003: 94)

$$
B I C_{k}^{\prime}=-G^{2}\left(M_{k}\right)+d f_{k}^{\prime} \ln N
$$

where $G^{2}\left(M_{k}\right)$ indicates the LR chi-squared statistic of the model M that has k regressors which is calculated as $-2 *\left(\log L_{0}-\log L_{k}\right)\left(\log L_{0}\right.$ indicates the $\log$ likelihood for a model that constraints all the parameters except for the intercept to be zero, while $\log L_{k}$ indicates the $\log$ likelihood of a given model with $\mathrm{k}$ regressors). $d f_{k}^{\prime}$ is the number of $\mathrm{k}$ regressors in the model and $\mathrm{N}$ is the number of cases. Basically the model with the more negative BIC' fits the data better than the model with the less negative BIC'.

\section{RESULTS}

\section{Kaplan-Meier Estimates of Proportion of Korean Men Who Remained Single}

Before examining the results of discrete-time hazard models, we discuss Kaplan-Meier estimates of age-specific proportion of never-married men (i.e., those who remained single) by educational attainment and cohort in Table $2 .^{6}$ Kaplan-Meier estimates present the estimated proportion of subjects who have not experienced an event (i.e., survived) until a specific time point and are calculated with the following equation (applied to our study of transition to marriage) (Kaplan and Meier 1958):

$$
\hat{S}\left(t_{i}\right)=\prod_{t_{i} \leq t}\left(1-\frac{d_{i}}{n_{i}}\right)
$$


where $n_{i}$ is the number of men at the risk of transition to marriage at the beginning of age $t_{i}, d_{i}$ is the number of men who married during the age $t_{i}$. When cases are censored at time $t_{i}$, those censored cases are dropped from the number of cases at the risk at the next time interval. Note that because we follow up respondents from the age 18 to 39 , there is no censored case for the two older cohorts born between 1946 and 1955 and between 1956 and 1966. In other words, for the two older cohorts, Kaplan-Meier estimates are actual proportions of men who remained single by a given age in the data. For the latest cohort born between 1966 and 1975, there are some cases censored for the age range from 36 to 39. However, the share of respondents in the latest cohort who were censored after 35 is only 11 percent. Although we could present agespecific proportions for all single ages from 18 to 39 , for simplicity we present proportions only at the ages $25,30,35$, and 39 .

\section{TABLE 2 ABOUT HERE}

In Table 2, we first discuss the relationship between education and marriage focusing on the earliest cohort (1946-55). The proportion of men who remained single by the age 25 is higher among those with higher education. However, the educational differences are reduced substantially at the age 30 , and then are actually reversed at the age 35 . Eventually, the proportion of men who remained single by the age 39 becomes smaller for those with higher levels of education than those with lower education: 5 percent of Korean men with less than high school education remained single by the age 39 , while only 3 percent of men with a university degree did so. In other words, the pattern of educational differences across ages in Table 2 
clearly illustrate that those with higher education delayed marriage but caught up and eventually were more likely to be married than their counterparts with lower education.

Turning to changes across cohorts, evident is that the proportion of men who remained single by a given age has increased across cohorts and also in all educational groups. By the age 25,72 percent of those with less than high school education in the earliest cohort remained single, while 85 percent of those with less than high school in the latest cohort did so. Similarly, the corresponding change among men with a university degree was from 87 percent to 96 percent. The increase in the proportion of never-married men across cohorts, however, did not alter the positive relationship between education and marriage at age 35 and 39. 44 percent of the latest cohort with less than high school remained single by the age 39 , while 15 percent of the latest cohort with a university degree remained single. In other words, the catching-up pattern by men with higher education remained across cohorts, even though men increasingly delayed marriage regardless of their educational levels.

One notable finding, however, is worth attention in Table 2. Although the increasing delay in marriage across cohorts is found for all educational groups, the degree of delay in marriage is particularly evident among men with lower levels of education. By the age 39,44 percent of the latest cohort with less than high school remained single, almost nine times the corresponding percentage (5\%) for the earliest cohort with less than high school. For those with a high school diploma only, the percentage of men who remained single by the age 39 increased from 3.5 percent for the earliest cohort to 25 percent (seven times). Meanwhile, the percentage of never-married men by the age 39 for those with a university degree increased less substantially, than the increase for men with high school only or less than high school, from 3 percent to 15 percent (five times). In the result, the difference between men with the highest and 
lowest levels of education in the proportion of never-married men by the age 39 diverged from only 2 percentage points (5.0\% vs. $2.8 \%$ ) for the earliest cohort to 29 percentage points ( $43.7 \%$ vs. $14.7 \%$ ) for the latest cohort. We expect that many of them, who remained single by age 39, would be never married. In other words, we see that the trend toward not only delayed but also forgone marriage has been more prominent for men with the lowest level of education than their counterparts with the highest level.

\section{The Results of Discrete-Time Hazard Models}

\section{TABLE 3 ABOUT HERE}

With Table 3, we now turn to the results of discrete-time hazard models that control for school enrollment in addition to interactions among duration, cohort, and educational attainment. The negative coefficients of cohorts in Model 1 indicate that two more recent cohorts were significantly less likely to marry than the earliest cohort of Korean men born between 1946 and 1955. The coefficients for educational attainment show that compared to those with a high school diploma only (reference), men who did not graduate from high school had lower odds of marriage, but those with a junior college degree or a university degree had higher odds. The linearly increasing odds of marriage along with the increasing level of education are consistent with the positive relationship between education and marriage observed in Kaplan-Meier estimates at the age 39 in Table 2. The negative coefficient of school enrollment confirms the difficulty of combining study and family. 
In order to examine whether the effect of education on marriage changed across cohorts, Model 2 includes interaction terms between cohort and education. First of all, a more negative BIC' value of Model 2 (-92020) than that of Model 1 (-91730) suggests that Model 2 fits the data better. Also, most of the interaction terms between cohort and education are statistically significant. Given that the coefficient of less than high school is positive (0.038), increasingly negative coefficients of less than high school for the 1956-65 cohort (-0.189) and for the 1966-75 cohort $(-0.526)$ indicate that the lower odds of marriage among men with less than high school relative to me with high school education only became more evident. On the other hand, increasingly positive coefficients of junior college and university across cohorts suggest that the higher odds of marriage among men with either a junior college or a university degree than among men with a high school diploma only became more evident. To facilitate visual understanding of changing education coefficients across cohorts, in Figure 1 we present separate coefficients of three educational levels (relative to high school) in each birth cohort by translating interaction terms. In Figure 1, it is clear that the gap in the odds of marriage between men with high school education and men with a junior college or a university degree increased across cohorts as well as the gap between men with high school education and men with less than high school increased. ${ }^{7}$

\section{FIGURE 1 ABOUT HERE}

Model 3 adds interaction terms between duration and education to Model 2, allowing us to assess the extent to which the effect of education on marriage varied across duration (age). The comparison of BIC' values between Model 2 and Model 3 indicates that adding interaction 
terms between duration and education significantly improves the mode fit. Stated differently, the effect of education did vary across duration (age). To ease interpretation of the interaction terms, we present the result of Model 3 as survival curves that display the proportion of men who remained single at each age, following Ramyo's (2003) and Park et al. (2013)'s strategy. These cumulated probabilities of remaining single were calculated on the basis of predicted marriage probabilities at each age (duration), which were originally calculated with the coefficients from Model 3. Figure 2 shows survival curves for four educational groups, separately, after taking into account cohort and enrollment. Specifically, the figure is for the earliest cohort members (1946-55) who were not enrolled. The figure clearly illustrates the pattern of changing relationship between education and marriage across ages (duration): convergence of the proportion of never-married men until around the age 30 and then divergence in a reversal pattern. Although most of the earliest cohort regardless of education eventually married by the age 39, we can still see the positive relationship between education and marriage.

\section{FIGURE 2 ABOUT HERE}

To relax the assumption that between-cohort differences in transition to marriage should be constant across ages (duration), Model 4 includes additional interaction terms between

duration and cohort. ${ }^{8}$ Model 4 has a more negative BIC' value (-94882) than Model 3 (-94466), suggesting that all two-way interactions among cohort, education, and duration are needed. Model 5 even allows full three-way interactions among cohort, education, and duration, rendering it to be most flexible model. The most negative BIC' value (-95947) of Model 5 indicates the all three-way interaction terms as well as all two-way are needed to fully describe 
Korean men's marriage pattern by education, cohort, and duration. Similar to the result for Model 3 above, interactions coefficients in Model 5 are difficult to grasp an overall pattern of changes in the effect of education across cohorts and over duration. Therefore, similar to Figure 2, we present a figure that graphically summarizes the result of the final model (Model 5) with predicted proportions of Korean men who remained single by duration since the age 18 for each level of educational attainment, calculated on the coefficients of Model 5 in Table 3. For the curves in Figure 3, we fixed school enrollment status as being not in school. In principle, the figure would need 12 curves for three cohorts for four educational groups per cohort, which would make the figure difficult to read. Therefore, for easy of presentation we exclude the survival curves for those with a junior college degree, which are mostly between curves for university and curves for high school. In the end, there are total nine survival curves (three educational groups for three cohorts).

\section{FIGURE 3 ABOUT HERE}

In each cohort, survival curves for different educational groups cross over at a point of duration. Before the point of crossing over, those with higher levels of education show the higher proportion of remaining single and after the crossing point, the pattern is reversed. In other words, despite the different ages at which different educational groups cross over, basically the pattern of catching up by those with higher levels of education is found consistently across cohorts. Having said this commonality across cohorts, however, notable is the enlarging gap among educational groups across cohorts. For the earliest cohort, Model 5 estimates the percentage of never-married men by the age 39 to be 4.8 percent, 3.4 percent, and 2.6 percent for 
men with less than high school, high school only, and university education. For the latest cohort, the corresponding percentages are estimated to be 43.1 percent, 24.6 percent, and 14.3 percent. The percentages are very similar to those from Kaplan-Meier estimates in Table 2. The proportion of remaining single by the age 39 increased from the earliest to the latest cohort by nine times for those with less than high school, seven times for those with a high school diploma only, and less than six times form those with a university degree. Due to the more substantial increase among those with the lowest level of education than those with the highest, the gap in the proportion between the highest and the lowest educated increased from 2.2 percentage points (4.8\% vs. $2.6 \%$ ) for the earliest cohort to 29 percentage points (43.1\% vs. $14.3 \%$ ). Figure 3 clearly shows how the gaps among educational groups in the proportion of remaining single by the age 39 diverged across cohorts. Note that although the divergence is particularly evident for the comparison between men with less than high school and those with university education, the gap between men with high school education only and those with university education has also enlarged.

\section{CONCLUSION}

Most of all, our result clearly shows the changing relationship between education and marriage by age among Korean men. The pattern suggests that statistical models assuming constant differentials across duration by educational attainment are inappropriate in describing the relationship between education and marriage among Korean men. Although at younger ages the proportion of never-married Korean men is higher among those with higher levels of education, the crossover happens around the age 30 from which the proportion of never-married men becomes smaller for men with higher levels of education than their counterparts with lower 
levels of education. In other words, highly educated men delay marriage until later ages but catch up to the extent that they are eventually more likely to marry than the low educated. In other words, consistent with evidence in the United States, men's education, an important indicator of economic prospects, is positively related to marriage in Korea.

Our comparison of the relationship between education and marriage across three birth cohorts reveals that recent cohorts are more likely to delay and avoid marriage than the earlier cohorts. Moreover, this trend toward the delay and avoidance of marriage is observed across all educational groups. However, the tendency of late and less marriage has been particularly significant for men with less than high school and (to a lesser extent) also for men with high school education only compared to men with a university degree. The likelihood of marriage by the age 39 has increasingly diverged between men with a university and men with the lowest two levels of education. This pattern among Korean men with lower levels of education is similar to the pattern of the retreat from marriage among those with lower levels of education in the United States (Ellwood and Jencks 2004; Manning et al., 2013).

Deteriorating economic prospects of Korean men with no college education, along with rapid expansion of higher education and the advent of knowledge and information-based economy, have likely increased difficulty for the low educated to make economic independence and establish a stable job career, which in turn have negatively affected marriage chances of the low educated. In a society like Korea where the male breadwinner model, although weakening, still prevails, the declining economic prospect of men with a low level of education may put the low educated particularly marginal positions in marriage market. Moreover, the rapid expansion of education among Korean women as well as men has likely added the disadvantage to the low educated men as Korean women prefer marrying up with respect to education (and other 
socioeconomic indicators). We also expected that the economic crisis, under which the latest cohort became the ages for marriage, should have aggravated the trend toward the growing educational gap in marriage.

Although our census data provide large samples with which we can examine long-term trends of marriage especially with four educational groups distinguished, it is a critical limitation that with the census data we were not able to look at the effects of other time-varying socioeconomic characteristics such as earnings and employment (Park et al. 2013). Although we reason that education is a particularly important indicator for men's socioeconomic status in Korea, it would be still useful to see how the effects of other socioeconomic characteristics have changed across cohorts. For instance, by simultaneously examining the effects of income and employment patterns on men's marriage, Kalmijin (2011) could look at more closely underlying mechanisms through which men's socioeconomic status affects marriage. However, without two or more longitudinal datasets for different cohorts, it is not feasible to examine trends in the effects of men's socioeconomic status. Although limited with focus on education only, therefore, our study is still meaningful to provide a long-term perspective on the issue.

Note that in this study were not able to identify marriages between Korean men and foreign women. One of the major demographic changes since the late 1990s in Korea is the steady increase of marriages between Koreans and foreign spouses. Since the mid-2000s, about one out of ten marriages is such type of marriage (Lee 2014). The majority of 'international' marriages involve marriages between Korean men and migrant women from China and SouthEast Asian countries. Importantly, those Korean men who marry migrant women disproportionally suffer from poor socioeconomic conditions (Lee 2014). Given their poor economic prospects, many of those Korean men are considerably marginalized in marriage 
market and could have remained single for much longer if there was no possibility of international marriage. In other words, the increased availability of international marriages especially for Korean men with lower education could offset the divergence in marriage between those with the highest level and the lowest level of education. Future research should quantify the extent to which the educational gap in marriage was actually offset by the increase of international marriages.

Another potential line of research is to systematically investigate how much the reduced pool of potential spouses, along with educational expansion, actually explains the declining marriage among Korean men with the lowest level of education. In this study, we simply considered that the marriage market mismatch could contribute to the declining marriage rate among the lowest educated men. But future research can decompose the declining marriage rate into the part associated with changing preference for marriage and the other part associated with changing availability of potential spouses to gauge the relevance of the marriage market mismatch hypothesis in the Korean context. Raymo and Iwasawa's (2005) study for highly educated women in Japan can be a good guideline to address the issue for Korean men with the lowest level of education. 


\section{ENDNOTES}

${ }^{1}$ Woo's (2009) study, published in Korean, compared the effect of education on marriage between Korean men born before 1970 and after 1970 using data from a social survey. However, it lumped together all men born before 1970 into one cohort, and also seems to suffer from the relatively small sample size for the recent cohort particularly during the ages of 30s. Moreover, perhaps due to the sample size, the study did not distinguish men with less than high school from those with a high school diploma only. Therefore, the trends in the effect of education in Korea are yet to be assessed in a systematic way. In the present paper, we overcome these limitations using the large data from the census.

${ }^{2}$ In particular, the current study of Korean men complements our previous study, which applied the similar methods and research design to investigate marriage among Korean women (Park et al., 2013).

${ }^{3}$ We thank James Raymo for pointing out relevance of women's educational hypergamy for men's marriage.

${ }^{4}$ Although the marriage transition rates declined overall across three cohorts, the age patterns of transition rates are similar across the cohorts. Age-specific transition rates started to increase somewhat steeply around the age 25 to the peak around the age 30 , and declined since then.

${ }^{5}$ We did some sensitive analysis without adding the two more years for college graduates, and found similar patterns of changing relationship between education and marriage across cohorts as we present in the current paper.

${ }^{6}$ See Chang and Li (2011) and Park et al. (2013) for a similar strategy for Taiwanese and Korean women, respectively.

${ }^{7}$ The star markers in the figure indicate statistical significance $(* * * \mathrm{p}<.00 * * \mathrm{p}<.01 * \mathrm{p}<.05)$ of the difference between high school and each educational level within each birth cohort.

${ }^{8}$ As mentioned before, the locations of knots were similar across three cohorts. 


\section{REFERENCES}

Becker, G. S. (1981). A treatise on the family. Cambridge, MA: Harvard University Press.

Brinton, M. C. (2001) (ed). Women's working lives in East Asia. Stanford, CA: Stanford University Press.

Burstein, N. R. (2007). Economic influences on marriage and divorce. Journal of Policy Analysis and Management, 26, 387-429.

Cheon, B-Y. (2013). Growing inequality and its' drivers in Korea. Democratic Society and Policy Studies 23, 15-40 (in Korean).

Cherlin, A. (2013). In the season of marriage, a question. Why bother? The New York Times, April 28 (page SR7).

Chang, Y-C., \& Li, A. J-C. (2011). Trends and educational differentials in marriage formation among Taiwanese women. WR-891. Santa Monica, Calif: RAND Corporation. As of November 11, 2011: http://www.rand.org/pubs/working_papers/WR891

Choe, M. K. (1998). Changing marriage patterns in South Korea. In: K. Mason, N. Tsuya \& M. Choe (Eds), The changing family in comparative perspective: Asian and the United States (pp. 43-62). Honolulu, Hawaii: University of Hawaii Press.

Ellwood, D. T., \& Jencks, C. (2004). The spread of single-parent families in the United States since 1960. Pp. 25-65 in D.P. Moynihan, T.M. Smeedin, \& L. Rainwater (eds.), The Future of the Family. New York: Russell Sage Foundation.

Fisher, C., \& Hout, M. (2006). A century of difference. New York: Russell Sage.

Fukuda, S. (2013). The changing role of women's earnings in marriage formation in Japan. The ANNALS of the American Academy of Political and Social Science, 646, 107-128.

Goldstein, J. R., \& Kenney, C. T. (2001). Marriage delayed or marriage forgone? New cohort forecasts of first marriage for U.S. women. American Sociological Review, 66, 506-519.

Harknett, K., \& Kuperberg, A. (2011). Education, labor markets and the retreat from marriage. Social Forces, 90, 41-63.

Hong, D-S. (2003). Social change and stratification. Social Indicators Research 62-63: 39-50.

Hyun, J. K., \& Lim, B-I. (2005). The financial crisis and income distribution in Korea: The role of income tax policy. The Journal of the Korean Economy, 6, 51-65.

Jomo, K. S. (2006). Growth with equity in East Asia? DESA Working Paper No. 33.

Kalmijn, M. (2011). The influence of men's income and employment on marriage and 
cohabitation: Testing Oppenheimer's theory in Europe. European Journal of Population, $27,269-293$.

Kaplan, E.L., \& Meier, P. (1958). Nonparametric estimation from incomplete observations, Journal of the American Statistical Association, 53, 457-481.

Korean Statistical Information Service (KOSIS) (2013). Statistical database: Economically active population survey. Available from http://kosis.kr/eng/database/database_001000.jsp?listid=B\&subtitle=Employment/Labor/ Wage (accessed October 23, 2013).

Kye, B., \& Mare, R. D. (2012). Intergenerational effect of shifts in women's educational distribution in South Korea: Transmission, differential fertility, and assortative mating. Social Science Research, 41, 1495-1514.

Lichter, D. T., McLaughlin, D. K., \& Ribar, D. C. 2002. Economic restructuring and the retreat from marriage. Social Science Research, 31, 230-56.

Linn, A. (2013). Marriage as a 'luxury good': The class divide in who gets married and divorced. Today (October 26). Retrieved from http://www.today.com/money/marriage-luxurygood-class-divide-who-gets-married-divorced-8C11457474.

Llyod, K. M., \& South, S. J. (1996). Contextual influences on young men's transition to first marriage. Social Forces, 74, 1097-1119.

Long, J. S., \& Freese, J. (2003). Regression models for categorical dependent variables using Stata. College Station, TX: Stata Press.

Manning, W. D., Brown, S. L., \& Payne, K. K. (2013). Two decades of stability and change in age at first union formation. Working Paper Serios WP-13-06. National Center for Family \& Marriage Research. Bowling Green State University.

Oppenheimer, V. K., Kalmijn, M., \& Lim, N. (1997). Men's career development and marriage timing during a period of rising inequality. Demography, 34, 311-330.

Oppenheimer, V. K. (2003). Cohabiting and marriage during young men's career-development process. Demography, 40, 127-149.

Organization for Economic Cooperation and Development (OECD). (2012). OECD employment outlook 2012. Paris: OECD Publishing.

Park, H. (2007a). Inequality of educational opportunity in Korea by gender, socio-economic background, and family structure. International Journal of Human Rights, 11, 179-197.

Park, H. (2007b). South Korea: Educational expansion and inequality of opportunity for higher 
education. Pp. 87-112 in Y. Shavit, R. Arum, and A. Gamoran (eds.), Stratification in Higher Education: A Comparative Study. Stanford, CA: Stanford University Press.

Park, H. (2013). The transition to adulthood among Korean youths: Transition markers in productive and reproductive spheres. The ANNALS of the American Academy of Political and Social Science, 646, 129-148.

Park, H., Lee, J. K, \& Jo, I. (2013). Changing relationships between education and marriage among Korean women. Korean Journal of Sociology, 47, 51-76.

Park, H., \& Raymo, J. M. (2013). Divorce in Korea: Trends and educational differentials. Journal of Marriage and Family, 75, 110-126.

Raymo, J. M. (2003). Educational attainment and the transition to first marriage among Japanese women. Demography, 40, 83-103.

Raymo, J. M., \& Iwasawa, M. (2005). Marriage market mismatches in Japan: An alternative view of the relationship between Women's education and marriage. American Sociological Review, 70, 801-822.

Schoen, R., \& Cheng, Y-H. A. (2006). Partner choice and the differential retreat from marriage. Journal of Marriage and Family, 68, 1-10.

Shin, K-Y. (2012) Economic crisis, neoliberal reforms, and the rise of precarious work in South Korea. American Behavioral Scientist published online 3 December.

Statistics Korea. (2011). Marriage and divorce statistics 2010: Press releases. Daejeon, Korea: Statistics Korea (in Korean).

Sweeney, M. M. (2002). Two decades of family change: The shifting economic foundations of marriage. American Sociological Review, 67, 132-147.

Torr, B. M. (2011). The changing relationship between education and marriage in the United States, 1940-2000. Journal of Family History, 36, 483-503

US Census Bureau (2011). Table MS-2. Estimated median age at first marriage, by sex: 1890 to the present. Internet release date: November 2011, accessed May 1, 2013 through http://www.census.gov/population/socdemo/hh-fam/ms2.xls

Xie, Y., Raymo, J. M., Goyette, K., \& Thornton, A. (2003). Economic potential and entry into marriage and cohabitation. Demography, 40, 351-367.

Woo, H. (2009). The impact of educational attainment on first marriage formation: Marriage delayed or marriage forgone? Korea Journal of Population Studies, 32, $25-50$ (in Korean). 
Yang, J., \& Ban, G. (2012). Changes in labor markets of 30s and their implications. Issue Paper 2012-3. Korea Research Institute for Vocational Education \& Training (KRIVET). Seoul: KRIVET (in Korean).

Yoon, H. The effect of Korean economy's structure change after 1990s on poverty structure and its policy implication. KDI Focus 14, 1-8 (in Korean). 
Figure 1. The Cofficients of Education (Relative to High School) in Each Birth Cohort

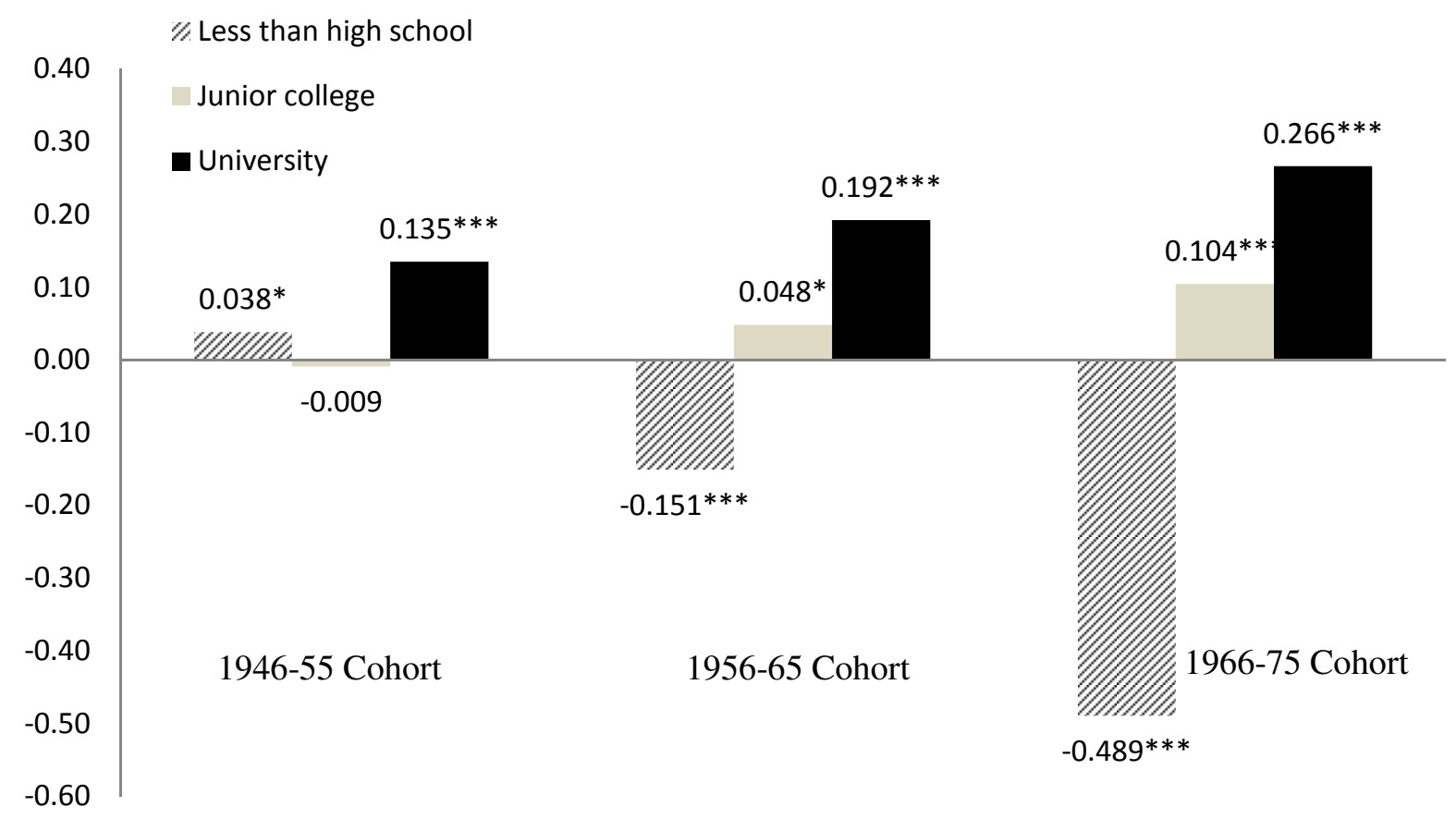


Figure 2. Predicted Proprtions of Korean Men Who Remained Single by Age and Education (the 1946-55 cohort, from Model 3 in Table 2)

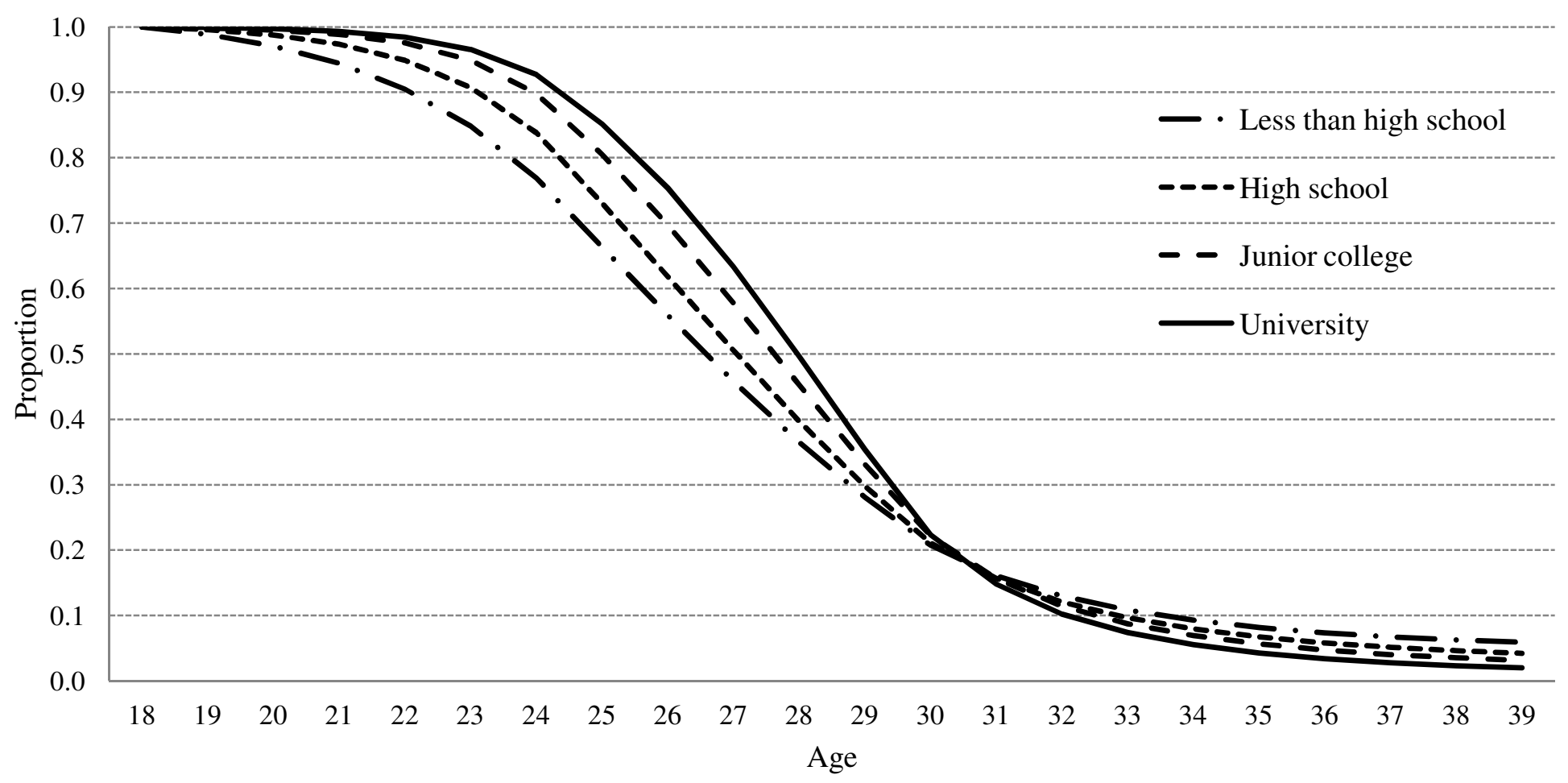


Figure 3. Predicted Proportions of Korean Men Who Remained Single by Age, Education, and Cohort (from Model 5 in Table 2)

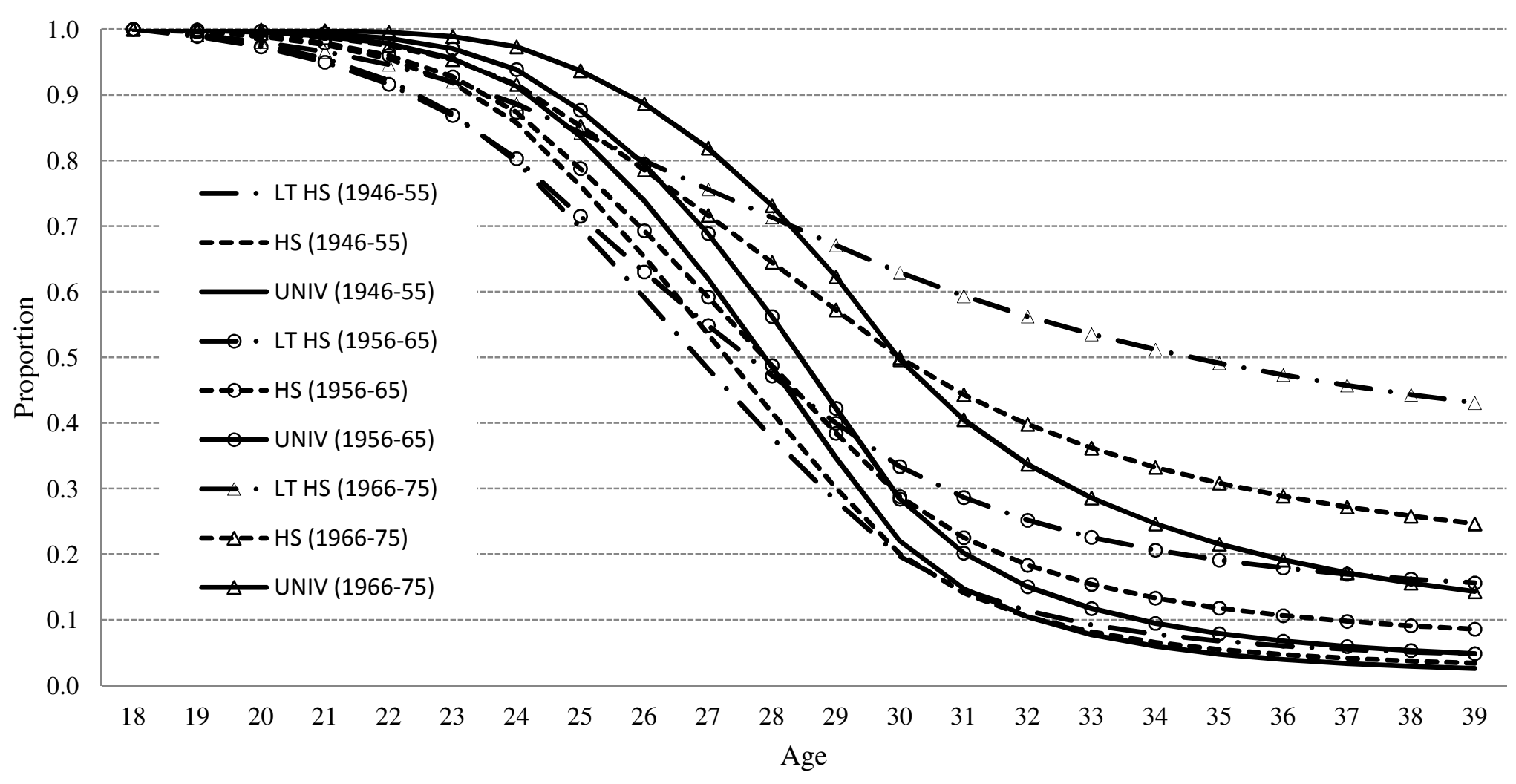


Table 1. Descriptive Statistics of Person-Year Data of Korean Men

\begin{tabular}{lrrrr}
\hline \hline & \multicolumn{4}{c}{ Birth Cohort } \\
& Total & $1946-55$ & $1956-65$ & $1966-75$ \\
\hline Educational Attainment (\%) & & & & \\
$\quad$ Less than high school & 19.1 & 43.1 & 21.1 & 5.8 \\
$\quad$ High school & 40.8 & 35.7 & 42.3 & 42.1 \\
$\quad$ Junior college & 12.2 & 4.9 & 10.2 & 17.5 \\
$\quad$ University & 27.9 & 16.4 & 26.4 & 34.7 \\
& & & & \\
School Enrollment (\%) & 25.1 & 17.0 & 25.3 & 28.8 \\
& & & & \\
Event of marriage (\%) & 7.4 & 9.5 & 8.1 & 5.8 \\
& & & & 529,323 \\
\hline
\end{tabular}

Source: Authors' own calculation using data from the 2010 Korean Census 
Table 2. Age-Specific Proportions of Never-Married Men by Birth Cohort and Education (Kaplan-Meier Estimates)

\begin{tabular}{|c|c|c|c|c|}
\hline \multirow[b]{2}{*}{ Age } & \multirow[b]{2}{*}{ Educational Attainment } & \multicolumn{3}{|c|}{ Birth Cohort } \\
\hline & & $1946-55$ & $1956-65$ & 1966-75 \\
\hline \multirow{4}{*}{25} & LT High school & 0.716 & 0.731 & 0.850 \\
\hline & High school & 0.786 & 0.809 & 0.870 \\
\hline & Junior college & 0.827 & 0.868 & 0.929 \\
\hline & University & 0.871 & 0.909 & 0.959 \\
\hline \multirow{4}{*}{30} & LT High school & 0.196 & 0.325 & 0.615 \\
\hline & High school & 0.201 & 0.286 & 0.488 \\
\hline & Junior college & 0.216 & 0.286 & 0.495 \\
\hline & University & 0.232 & 0.298 & 0.507 \\
\hline \multirow{4}{*}{35} & LT High school & 0.071 & 0.197 & 0.495 \\
\hline & High school & 0.057 & 0.122 & 0.316 \\
\hline & Junior college & 0.059 & 0.099 & 0.261 \\
\hline & University & 0.052 & 0.081 & 0.216 \\
\hline \multirow{4}{*}{39} & LT High school & 0.050 & 0.158 & 0.437 \\
\hline & High school & 0.035 & 0.087 & 0.249 \\
\hline & Junior college & 0.034 & 0.068 & 0.193 \\
\hline & University & 0.028 & 0.050 & 0.147 \\
\hline
\end{tabular}

Source: Authors' own calculation using data from the 2010 Korean Census 
Table 3. Discrete-Time Hazard Models of Transition to First Marriage among Korean Men

\begin{tabular}{|c|c|c|c|c|c|}
\hline & M1 & M2 & M3 & M4 & M5 \\
\hline \multicolumn{6}{|l|}{ Duration (since the age 18) } \\
\hline D1 (0-6 years) & $0.500^{* * *}$ & $0.502^{* * *}$ & $0.582^{* * *}$ & $0.609^{* * *}$ & $0.574^{* * *}$ \\
\hline D2 (7-11 years) & $0.228^{* * *}$ & $0.229^{* * *}$ & $0.205^{* * *}$ & $0.268^{* * *}$ & $0.277^{* * *}$ \\
\hline D3 (12+ years) & $-0.159^{* * *}$ & $-0.158^{* * *}$ & $-0.163^{* * *}$ & $-0.192^{* * *}$ & $-0.185^{* * *}$ \\
\hline \multicolumn{6}{|l|}{ Cohort (ref: 1946-55) } \\
\hline $1956-65$ & $-0.330^{* * *}$ & $-0.271^{* * *}$ & $-0.267^{* * *}$ & $0.203^{* *}$ & -0.101 \\
\hline $1966-75$ & $-0.906^{* * *}$ & $-0.874^{* * *}$ & $-0.862^{* * *}$ & $-0.467^{* * *}$ & $-0.668^{* * *}$ \\
\hline \multicolumn{6}{|l|}{ Education (ref: high school: HS) } \\
\hline Less than high school (LT HS) & $-0.087^{* * *}$ & $0.038^{*}$ & $1.113^{* * *}$ & $1.253^{* * *}$ & $0.923^{* * *}$ \\
\hline Junior college (JC) & $0.076^{* * *}$ & -0.009 & $-1.176^{* * *}$ & $-1.266^{* * *}$ & -0.506 \\
\hline University (UV) & $0.225^{* * *}$ & $0.135^{* * *}$ & $-1.781^{* * *}$ & $-1.866^{* * *}$ & $-1.069^{* * *}$ \\
\hline \multicolumn{6}{|l|}{ Cohort X Education } \\
\hline 1956-65 x LT HS & & $-0.189^{* * *}$ & $-0.121^{* * *}$ & $-0.141^{* * *}$ & $0.357^{* *}$ \\
\hline 1966-75 x LT HS & & $-0.526^{* * *}$ & $-0.396^{* * * *}$ & $-0.410^{* * *}$ & $0.749^{* * *}$ \\
\hline $1956-65$ x JC & & 0.057 & 0.032 & 0.061 & -0.534 \\
\hline $1966-75 \times \mathrm{JC}$ & & $0.113^{* *}$ & 0.044 & $0.079^{*}$ & $-1.115^{* *}$ \\
\hline $1956-65$ x UV & & $0.057^{*}$ & 0.035 & $0.084^{* *}$ & $-0.551^{*}$ \\
\hline $1966-75$ x UV & & $0.131^{* * *}$ & $0.052^{*}$ & $0.118^{* * *}$ & $-1.618^{* * *}$ \\
\hline \multicolumn{6}{|l|}{ Duration X Education } \\
\hline D1 x LT HS & & & $-0.148^{* * *}$ & $-0.158^{* * *}$ & $-0.112^{* * *}$ \\
\hline D2 x LT HS & & & $-0.046^{* * *}$ & $-0.079^{* * *}$ & $-0.061^{* * *}$ \\
\hline D3 x LT HS & & & $-0.028^{* * *}$ & -0.003 & -0.023 \\
\hline D1 x JC & & & $0.133^{* * *}$ & $0.182^{* * *}$ & 0.044 \\
\hline $\mathrm{D} 2 \mathrm{xJC}$ & & & $0.085^{* * *}$ & $0.120^{* * *}$ & $0.053^{*}$ \\
\hline D3 x JC & & & 0.009 & 0.001 & 0.008 \\
\hline D1 x UV & & & $0.182^{* * *}$ & $0.184^{* * *}$ & $0.107^{* *}$ \\
\hline D2 x UV & & & $0.172^{* * *}$ & $0.183^{* * *}$ & $0.091^{* * *}$ \\
\hline D3 x UV & & & $0.024^{* * *}$ & $0.016^{* *}$ & 0.019 \\
\hline
\end{tabular}


(Table 3 continued)

Duration X Cohort

D1 x 1956-65

D2 x 1956-65

$-0.050^{* * *} \quad-0.006$

D3 x 1956-65

$-0.059^{* * *} \quad-0.052^{* * *}$

D1 x 1966-75

D2 x 1966-75

D3 x 1966-75

$0.003 \quad-0.005$

$\begin{array}{ll}-0.026 & 0.020\end{array}$

$-0.107^{* * *}-0.143^{* * *}$

$0.066^{* * *} \quad 0.061^{* * *}$

Duration X Cohort X Education

D1 x 1956-65 x LT HS

$-0.055$

D1 x 1956-65 x JC

0.074

D1 x 1956-65 x UV

0.062

D1 x 1966-75 x LT HS

$-0.179^{* * *}$

D1 x 1966-75 x JC

D1 x 1966-75 x UV

$0.144^{*}$

$0.184^{* * *}$

D2 x 1956-65 x LT HS

$-0.068^{* * *}$

D2 x 1956-65 x JC

0.036

D2 x 1956-65 x UV

$0.070^{* * *}$

D2 x 1966-75 x LT HS

$-0.024$

D2 x 1966-75 x JC

$0.078^{* *}$

D2 x 1966-75 x UV

$0.150^{* * *}$

D3 x 1956-65 x LT HS

$0.031^{*}$

D3 x 1956-65 x JC

$-0.011$

D3 x 1956-65 x UV

$-0.008$

D3 x 1966-75 x LT HS

$0.055^{* *}$

D3 x 1966-75 x JC

$-0.016$

D3 x 1966-75 x UV

$-0.010$

School enrolled

Constant

$$
\begin{array}{lll}
-0.901^{* * *} & -0.878^{* * *} & -0.155^{* * *} \\
-5.462^{* * *} & -5.514^{* * *} & -5.987^{* * *}
\end{array}
$$

$-0.148^{* * *}$

$-0.155^{* * *}$

$-6.293^{* * *}$

$-6.091^{* * *}$

\# of regressors

9

15

24

30

48

Log likelihood

$-275942.5$

$-275755.3$

$-274951.7$

$-274219.4$

$-274055.7$

BIC'

$-91730.2$

$-92020.4$

$-94466.3$

$-94882.1$

$-94957.0$

$* * * \mathrm{p}<.001 * * \mathrm{p}<.01 * \mathrm{p}<.05$ 